ISSN 0819-2642

ISBN 0734025947

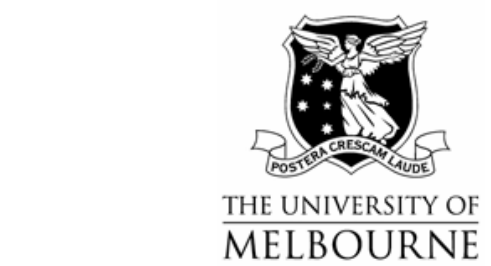

THE UNIVERSITY OF MELBOURNE

DEPARTMENT OF ECONOMICS

RESEARCH PAPER NUMBER 938

MARCH 2005

\title{
ADULT EQUIVALENCE SCALES, INEQUALITY AND POVERTY
}

by

John Creedy \&

Catherine Sleeman

Department of Economics The University of Melbourne Melbourne Victoria 3010 Australia. 


\title{
Adult Equivalence Scales, Inequality and Poverty ${ }^{1}$
}

\section{John Creedy and Catherine Sleeman}

\section{University of Melbourne and the Reserve Bank of New Zealand}

\begin{abstract}
This paper examines the sensitivity of inequality and poverty measures to the adult equivalence scale and the unit of analysis. Comparisons are made using parametric equivalence scales, and income units include individuals, equivalent adults and households. The role of the correlation between equivalent income and household size, and the weight attached to children, is examined analytically. Empirical results are based on New Zealand Household Expenditure Survey (HES) data for total expenditure. Further results using a variety of equivalence scales, for New Zealand, Australia, the UK and the OECD, are examined.
\end{abstract}

\footnotetext{
JEL Classification D31, D63, H23, I31, I32

Keywords $\quad$ Inequality; poverty; equivalence scales; living standard; income unit
}

\footnotetext{
${ }^{1}$ A first draft of this paper was written at the NZ Treasury. The views, opinions, findings, and conclusions or recommendations expressed in this paper are strictly those of the authors. They do not necessarily reflect the views of the New Zealand Treasury or the Reserve Bank of New Zealand. We should like to thank Nathan McLellan for helpful comments on an earlier draft of this paper.
} 


\section{Adult Equivalence Scales, Inequality and Poverty}

\section{Introduction}

Measures of inequality and poverty require populations that are demographically homogeneous so as to validly compare income levels across households. Demographic homogeneity is achieved by forming 'an (artificial) income distribution for a fictitious population’ Ebert (1997, p.235). ${ }^{2}$ The income distribution is created by adjusting household incomes using an adult equivalence scale, which provides a measure of 'living standard' that is comparable across households with differing compositions. The fictitious population is formed by defining a unit of analysis or income recipient, for whom a living standard can then be reported. This paper examines the sensitivity of several inequality and poverty measures to the choice of the adult equivalence scale and the unit of analysis. Using New Zealand data, the paper replicates the variability found in studies for other countries, and provides further general analytical insights into the nature of the variations, by considering the relevant joint distributions.

Section 2 defines the two-parameter functional form of the adult equivalence scale that is used to conduct the empirical analysis, and examines the use of the equivalent adult and the individual as feasible units of analysis. Earlier literature on these issues is also briefly discussed. Section 3 presents empirical comparisons of inequality for New Zealand for a variety of demographic groups. Analytical results are obtained concerning the effects of households' economies of scale in consumption, on the correlation between living standards and household sizes, and the effect on measured inequality of the 'weight attached to children' relative to adults.

Section 4 considers poverty measures, and examines the simultaneous increase in poverty and reduction in inequality that occurs when the 'economies of scale' parameter is raised. Section 5 examines the effects of alternative equivalence scales, and income units, on the degree of reranking observed when comparing pre-tax and post-tax distributions.

\footnotetext{
${ }^{2}$ Cowell (1984) discussed nine alternatives, arising from a distinction between three types of income recipient and three income measures.
} 
While reranking of unadjusted incomes is a deliberate aim of a tax and transfer system, reranking of equivalised incomes reduces the redistributive effects of taxation.

A variety of equivalence scales are used in practice. Section 6 examines a range of equivalence scales designed for New Zealand, the United Kingdom, Australia and the OECD. To provide comparable estimates of parameters, the two-parameter equivalence scale function is fitted to the various scales used, and the results are applied to the New Zealand data. Brief conclusions are provided in section 7.

\section{Alternative Concepts and Measures}

This section describes the equivalence scales, along with the inequality and poverty measures used in later sections. Subsection 2.1 defines the functional form of the equivalence scale. This function, while essentially pragmatic, is highly flexible and depends on only two easily-interpreted parameters. Subsection 2.2 compares the use of alternative units of analysis, and reviews the difficulty arising from the fact that for heterogeneous populations the basic equity principle involved in the 'principle of transfers' is inconsistent with an alternative principle of 'Pareto indifference' or anonymity.

\subsection{Adult Equivalence Scales}

Let $y_{i}$ denote the income of the $i^{\text {th }}$ household, for $i=1, \ldots, N$. The number of individuals in the household is described by $n_{i}$, while the household's demographic structure is denoted by the vector $d_{i}$, and provides the number of individuals in various demographic groups based on age and gender classifications. Using these definitions, the adult equivalent size of household $i$ may be expressed as: ${ }^{3}$

$$
m_{i}=m\left(n_{i}, d_{i}\right)
$$

This size is normalised so that $m(n=1, d=$ adult $)=1$. Household income is adjusted to obtain the equivalent income or 'living standard', defined by:

$$
z_{i}=\frac{y_{i}}{m_{i}}
$$

A household consisting of one adult with an income of $y$ therefore has the same 'living standard' as an n-person household with an income of $y \times m(n, d)$. Further progress

\footnotetext{
${ }^{3}$ The scales are considered to be independent of prices.
} 
requires the form of $m_{i}=m\left(n_{i}, d_{i}\right)$ to be specified. The following analysis uses a flexible form, which distinguishes between the number of adults, $n_{a, i}$, and children, $n_{c, i}$, such that:

$$
m_{i}=\left(n_{a, i}+\theta n_{c, i}\right)^{\alpha}
$$

The parameter, $\theta$, measures the size of children relative to adults, while $\alpha$ reflects economies of scale in consumption. This is an extension of the simple form, $n_{i}^{\alpha}$, used by Buhmann et al (1988) and Coulter et al (1992), modified by Cutler and Katz (1992), and used by, for example, Banks and Johnson (1994) and Jenkins and Cowell (1994). It is now widely used in empirical work and, as shown in section 6, provides a good approximation to other scales used.

\subsection{Units of Analysis}

One approach to defining a unit of analysis, proposed by Ebert (1997), is to use the 'adult equivalent person'. ${ }^{4}$ This approach assigns to each of the $m_{i}$ adult equivalent persons in household $i$, for $i=1, \ldots, N$, an equivalent income of $z_{i}$. The income concept and the unit of analysis are treated consistently, ensuring that each individual's contribution to inequality and poverty depends on the demographic structure of the household to which they belong. An adult in a one-person household for example 'counts for one', whereas the same adult in a multi-adult household counts for 'less than one'.

This approach also satisfies the basic equity principle, associated with the principle of transfers, which provides that a transfer of income from a poorer to a relatively richer household, that leaves the position of the richer household unchanged, causes inequality to rise. The fulfilment of this principle enables Lorenz and Generalised Lorenz curve analyses to be conducted from the resulting distribution.

An alternative approach is to treat the individual as the basic unit of analysis. ${ }^{5}$ This approach assigns the equivalent income of household $i, z_{i}$, to each of the $n_{i}$ individuals. Every person 'counts for one' irrespective of the demographic nature of the household to which they belong. This approach consequently has the property of anonymity, in that inequality and poverty measures remain unchanged when one individual in the population is replaced by another individual who has the same living standard but belongs to a

\footnotetext{
${ }^{4}$ A number of empirical studies have taken the household itself as the basic unit of analysis, which simply assigns to each household its equivalent income, $Z_{i}$.

5 Jorgenson and Slesnick (1984), Glewwe (1991) and Slesnick (1994) use this method. It is also preferred by Shorrocks (2004), Danziger and Taussig (1979) and Ringen (1991).
} 
different demographically structured household. This property was called the 'compensation principle' by Shorrocks (2004) and the 'Pareto indifference principle' by Decoster and Ooghe (2002).

The individual unit of analysis does not in general satisfy the equity principle of transfers. As shown by Glewwe (1991, p.213) and Decoster and Ooghe (2002, pp.3-4), a transfer of income from a poor to a relatively richer (and larger) household may actually reduce inequality and raise social welfare. The presence of economies of scale causes a large household to be regarded as being 'more efficient' at generating welfare. An important implication is that in the context of heterogeneous populations, the basic equity principle inherent in the principle of transfers and the concept of Lorenz dominance (whereby one Lorenz curve lies unambiguously closer to the diagonal of equality) are no longer equivalent. This equivalence is a fundamental component of welfare analysis for homogeneous populations. Consequently, the choice between individuals and adult equivalents as the basic unit of analysis involves a choice between two incompatible value judgements. They can in principle lead to opposite conclusions about the effects on inequality of a tax policy change. Examples of such conflicts using tax microsimulation models are given by Decoster and Ooge (2002) and Creedy and Scutella (2003).

\section{Inequality Analysis for New Zealand}

This section analyses the sensitivity of New Zealand's inequality and poverty measures to the equivalence scale parameters, $\theta$ and $\alpha$, and to the chosen unit of analysis. The analysis is conducted using data on the weekly expenditure levels of households, as opposed to incomes. The use of expenditure data may be thought to eliminate to some extent the effects of short term variations in income; on the use of expenditure rather than income data, see Blundell and Preston (1994, 1997), Attanasio and Japelli (1997) and Goodman and Oldfield (2004). From the Household Economic Survey, household expenditure data for the years 1995, 1996, 1997, 1998 and 2001, were adjusted to 2001 prices using the consumer price index (CPI). ${ }^{6}$ The surveys were then pooled to form one large data base containing the weekly total expenditure level of each household along with information about the household's structure.

\footnotetext{
${ }^{6}$ Surveys have only been conducted tri-annually since 1998.
} 


\subsection{Inequality Measures}

A range of inequality measures was examined, but similar results were obtained for all measures, so only those for the Atkinson inequality measure are reported here. ${ }^{7}$ Figures 1 and 2 show, for the two income units respectively, inequality plotted against the economies of scale parameter, $\alpha$, for four values of the weight attached to children parameter, $\theta$. The degree of constant relative inequality aversion used is 0.6. Although inequality increases as the degree of inequality aversion is raised, the general pattern remains unchanged.

These results replicate for NZ data the result, first shown using UK data, of Coulter et al (1992), who found that increasing the value of $\alpha$ has two opposing effects on measures of inequality. The first is the concentration effect whereby $\alpha$ is inversely related to inequality. As the value of $\alpha$ is increased from low values, economies of scale are reduced and as a result equivalent income falls proportionately more for relatively larger households. It is known that income and total expenditure are both positively correlated with household size. This implies that relatively richer households incur proportionately greater falls in equivalent income. The rise in $\alpha$ therefore has an equalising effect. Over low values of $\alpha$, Figures 1 and 2 display the inverse relationship produced by the concentration effect.

However, over higher values of $\alpha$, inequality is seen to rise with $\alpha$, producing a U-shaped inequality profile. The proportionately larger fall in equivalent income for the larger households, as $\alpha$ increases from an already high value, eventually leads to the kind of reranking effect identified by Coulter et al (1992), whereby the rank-order of households (when ranked by equivalent income) changes. The examples show that over higher values of $\alpha$, the reranking effect dominates the concentration effect, thereby causing inequality to rise. As observed by Jenkins and Cowell (1994), the reranking effect increases with the weight that is attached to children, $\theta$, and hence the inequality profiles for higher values of $\theta$ show much greater curvature.

\footnotetext{
${ }^{7}$ The Atkinson measure is defined as the proportional difference between the equally-distributed equivalent income, $\tilde{Z}$, and the arithmetic mean income, $\bar{Z}$. The term $\tilde{Z}$ is the living standard of a household which, if received by every 'unit of analysis' in the population, produces the same social welfare as the actual distribution, using an additive welfare function with weights $z^{1-\varepsilon} /(1-\varepsilon)$. Here $\varepsilon \neq 1$ is the degree of constant relative inequality aversion of a disinterested judge.
} 
Figure 1 - Inequality Sensitivity

Unit of Analysis: Individual

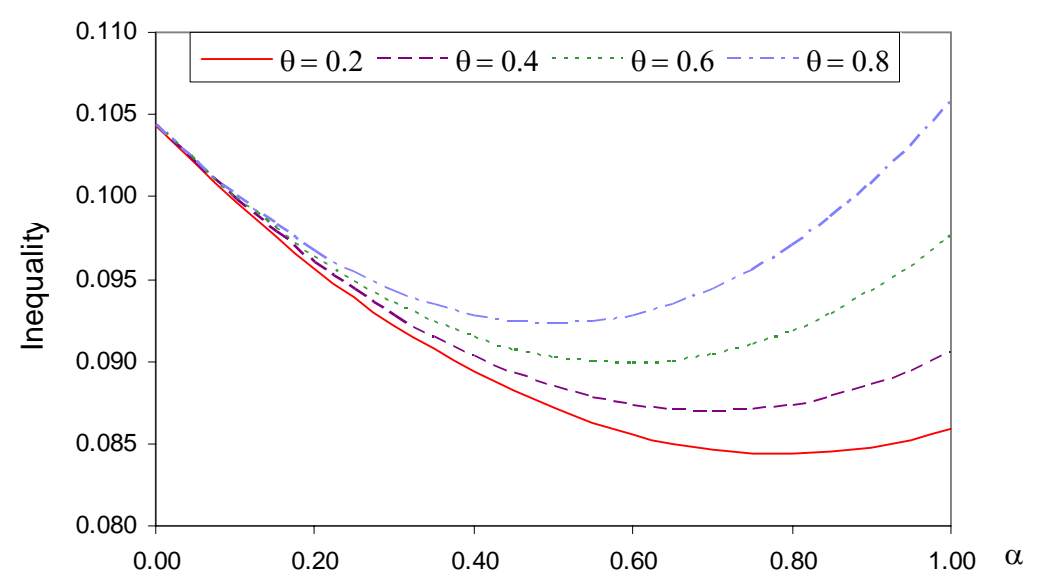

Figure 2 - Inequality Sensitivity

Unit of Analysis: Equivalent Adult

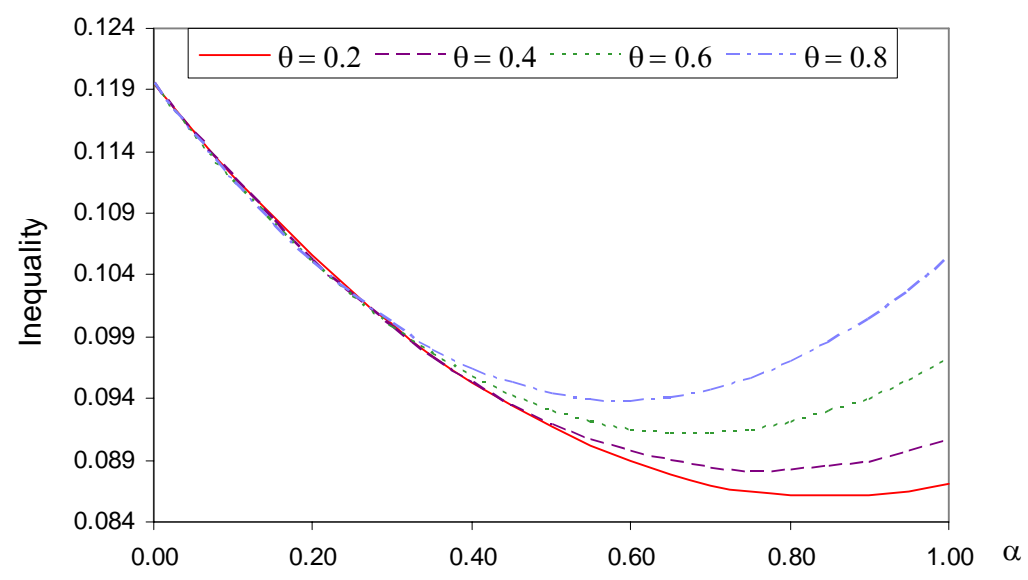

\subsection{Reranking and Joint Distributions}

Coulter et al (1992, p.1073) state that the reranking occurs, for the case where $\theta=1$, when the economies of scale parameter, $\alpha$, exceeds the inverse of the elasticity of household size with respect to income. This subsection shows how reranking is related to the point at which the correlation between equivalent income and household size becomes negative. Total income, $y_{i}$, is known to be positively correlated with household size, $n_{i}$, but the correlation between equivalent income, $z_{i}$, and household size, $n_{i}$, is parameter dependent. It is therefore useful to consider the condition under which the correlation coefficient, $\rho$, between $z_{i}$ and $n_{i}$ is negative, for the case, treated by Coulter et al (1992), where the adult equivalence scale is simply, $m_{i}=n_{i}^{\alpha}$. First, suppose that income and the number of persons in the income unit are jointly lognormally distributed as: 


$$
\Lambda\left(y, n \mid \mu_{y}, \mu_{n}, \sigma_{x}^{2}, \sigma_{n}^{2}, \rho_{y n}\right)
$$

Further results require the following general properties of the lognormal distribution. If $x$ is $\Lambda\left(x \mid \mu, \sigma^{2}\right)$ :

$$
E(x)=\exp \left(\mu+\sigma^{2} / 2\right)
$$

The power $x^{\delta}$ is distributed as $\Lambda\left(\delta \mu, \delta^{2} \sigma^{2}\right)$, and for two variables jointly distributed as $\Lambda\left(x, y \mid \mu_{x}, \mu_{y}, \sigma_{x}^{2}, \sigma_{y}^{2}, \rho_{x y}\right)$. Therefore, the ratio $x / y$ is distributed as:

$$
\Lambda\left(\frac{x}{y} \mid \mu_{x}-\mu_{y}, \sigma_{x}^{2}+\sigma_{y}^{2}-2 \rho_{x y} \sigma_{x} \sigma_{y}\right)
$$

The covariance between household size and equivalent income is, by definition:

$$
\operatorname{Cov}(z, n)=E\left(\frac{y}{n^{\alpha-1}}\right)-E\left(\frac{y}{n^{\alpha}}\right) E(n)
$$

Using the three properties give above, average adult equivalent income is:

$$
E\left(\frac{y}{n^{\alpha}}\right)=\exp \left\{\mu_{y}-\alpha \mu_{n}+\frac{1}{2}\left(\sigma_{y}^{2}+\sigma_{n}^{2}-2 \alpha \rho_{y n} \sigma_{y} \sigma_{n}\right)\right\}
$$

A similar result holds for $E\left(\frac{y}{n^{\alpha-1}}\right)$. It can be shown, after some manipulation, that:

$$
\operatorname{Cov}(z, n)=(\exp A)(\exp B-1)
$$

where:

$$
A=\mu_{y}+(\alpha-1) \mu_{n}+\frac{1}{2}\left(\sigma_{y}^{2}+\left(1+\alpha^{2}\right) \sigma_{n}^{2}-2 \alpha \rho_{y n} \sigma_{y} \sigma_{n}\right)
$$

and:

$$
B=\rho_{y n} \sigma_{y} \sigma_{n}-\alpha \sigma_{n}^{2}
$$

Thus the covariance is positive if $\exp B-1>0$, that is if $B>0$. Hence there is a positive correlation between adult equivalent income and the number of adults if:

$$
\rho_{y n} \frac{\sigma_{y}}{\sigma_{n}}>\alpha
$$

This condition is therefore simply interpreted in terms of the size of the regression coefficient in the linear regression relationship between logarithms of household size and income. It is precisely the elasticity condition mentioned by Coulter et al (1992). 
Figure 3 - Correlation Between Equivalent Income, $z_{i}$ and Household Size, $n_{i}$

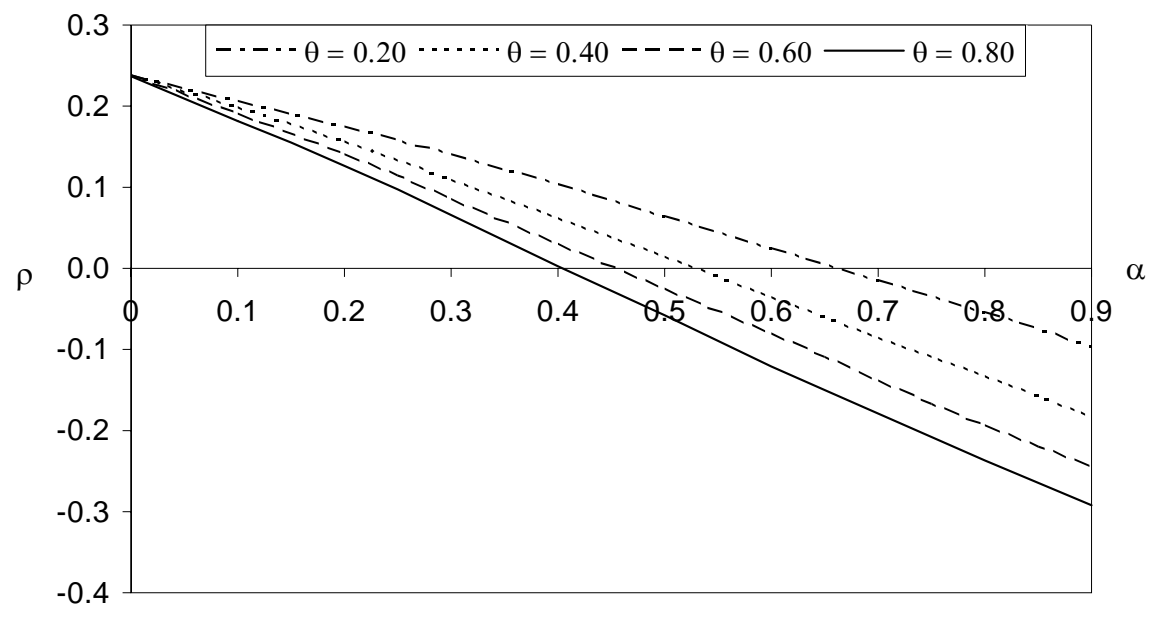

The present empirical analysis also allows for variations in the weight attached to children, $\theta$. Figure 3 shows the correlation coefficient, $\rho$, between $z_{i}$ and $n_{i}$ as $\alpha$ varies, for four values of $\theta$, where the unit of analysis is the individual. The correlation is initially positive, but falls as economies of scale are reduced and eventually becomes negative. Furthermore, the correlation falls faster for higher values of the parameter $\theta$. This is turn causes the correlation to turn negative (introducing reranking) earlier, so that the profile of inequality turns up earlier for higher values of $\theta$. This is reflected in Figures 1 and 2.

The correlation also affects comparisons between the inequality profiles for different income units. For any given household, $m_{i} \leq n_{i}$, which leads the equivalent adult unit to give proportionately more weight to smaller households when compared with the individual unit. As $\alpha$ rises and the correlation between $z_{i}$ and $n_{i}$ falls, smaller households enjoy increasingly larger equivalent incomes relative to larger households. Consequently, as $\alpha$ rises, inequality measures based on the equivalent adult unit fall relative to those based on the individual unit. This is seen in Figure 4, which shows the inequality measures for the equivalent adult and individual units in the case of a high inequality aversion coefficient of 1.2 when the weight attached to children is $\theta=0.8$. 
Figure 4 - Inequality Measures: $\theta=0.8$

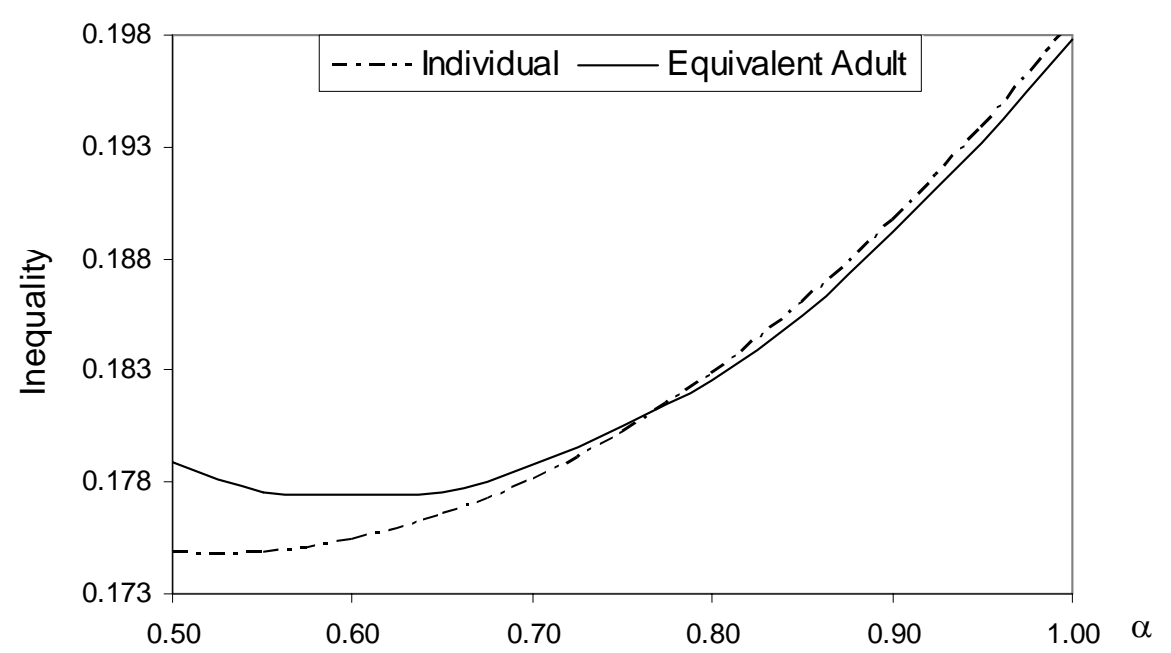

\subsection{The Weight Attached to Children}

Another finding from the sensitivity analysis is that, for all values of $\alpha$ and for a given unit of analysis, inequality is positively related to the weight attached to children, $\theta$. This result is independent of inequality aversion and the unit of analysis. The feature was suggested by Banks and Johnson (1994), but Cowell and Jenkins (1994, pp. 892-893) argued that the relationship need not necessarily be monotonic, although it 'may be difficult to characterise precisely from theoretical analysis alone'. However, some insight may be obtained as follows. The adult equivalent size of a household may be written, where for convenience subscripts for the household have been omitted, as:

$$
m=l^{\alpha}
$$

where:

$$
l=n_{a}+\theta n_{c}
$$

Assuming that the number of adults and the number of children are independent of each other, the variance of $l$ is described by: ${ }^{8}$

$$
\sigma_{l}^{2}=\sigma_{n a}{ }^{2}+\theta^{2} \sigma_{n c}{ }^{2}
$$

Hence $\sigma^{2}$, rises with $\theta$. Taking logs of equation (12) gives $\log m=\alpha \log l$ and the variance of $\log m$ is thus:

$$
\sigma_{\log m}^{2}=\alpha^{2} \sigma_{\log l}^{2}
$$

\footnotetext{
${ }^{8}$ Allowing for a positive correlation strengthens the effect of $\theta$.
} 
Movements in $\sigma_{l}^{2}$ and $\sigma^{2}{ }_{\log l}$ are monotonic, so the rise in $\sigma_{l}^{2}$ and hence in $\sigma^{2}{ }_{\log l}$ as a result of an increase in $\theta$ leads $\sigma_{\log m}^{2}$ to increase. It is then necessary to consider the effect of such an increase on the dispersion of equivalent income, given by $z=y / \mathrm{m}$. Taking logs gives $\log z=\log y-\log m$. The variance of logarithms of equivalent income is therefore:

$$
\sigma_{\log z}^{2}=\sigma_{\log y}^{2}+\sigma_{\log m}^{2}-2 \operatorname{cov}_{\log y, \log m}
$$

Hence, the dispersion, measured by the variance of logarithms of equivalent income, $\sigma_{\log z}^{2}$, rises with $\sigma_{\log m}^{2}$, which has been seen to rise with $\theta$. But the covariance term is also affected positively by $\theta$. Hence, although a positive effect has been found using the present data, it is possible in principle, over some range of parameter values, for the dispersion of equivalent income to fall as the weight attached to children increases.

\section{Poverty Measures}

This section considers the sensitivity of alternative poverty measures to the parameters of the adult equivalence scale. Results are reported here for two measures of poverty, although a wider range was considered. The poverty line beneath which individuals are judged to be in poverty is denoted $z_{p}$. The first measure, $P_{0}$, is the widely used headcount measure of poverty, which counts the proportion of individuals below the poverty line. The second measure, $P_{1}$, is equal to $P_{0}$ multiplied by $1-\bar{z}_{p} / z_{p}$, where $\bar{z}_{p}$ is the average income of those below the poverty line. Hence $P_{1}$ depends on the average depth of poverty as well as the number of individuals below the poverty line. These are the first two measures in the class of poverty measures introduced by Foster et al. (1984).

Variations in $P_{0}$ and $P_{1}$ are displayed in Figures 5 to 8, which show poverty against $\alpha$ (the economies of scale parameter) for four values of $\theta$ (the weight attached to children). Figures 5 and 6 use the individual as the unit of analysis, while Figures 7 and 8 use the child as the unit of analysis; this unit was chosen in view of the interest in child poverty. For each poverty measure and unit of analysis, the absolute poverty line, in terms of equivalent expenditure, was \$195 per week (the form of variation considered here does not depend on the poverty line). Clearly, poverty rises as a greater weight is attached to children and as the absolute poverty line is increased. ${ }^{9}$

\footnotetext{
${ }^{9}$ Coulter et al (1992) allow the poverty line to depend on equivalent adult size.
} 
Figure 5 - Individual $P_{0}$

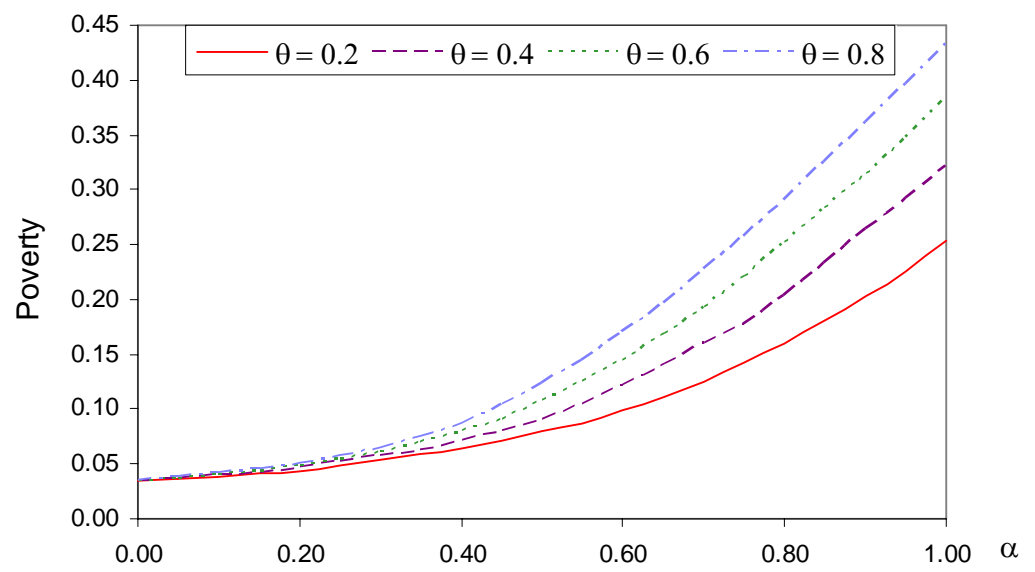

Figure 7 - Child $P_{0}$

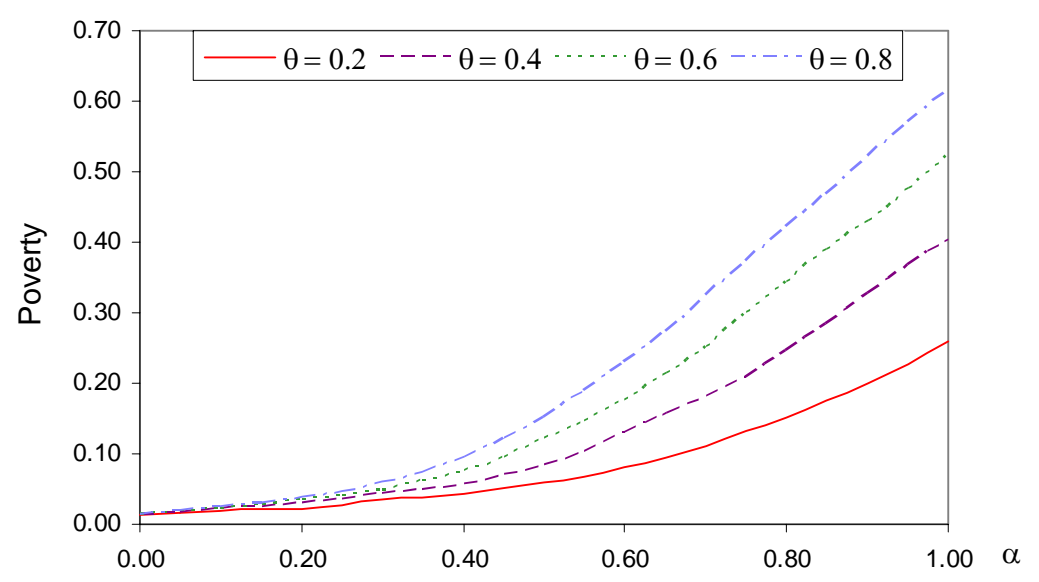

Figure 6 - Individual $P_{1}$

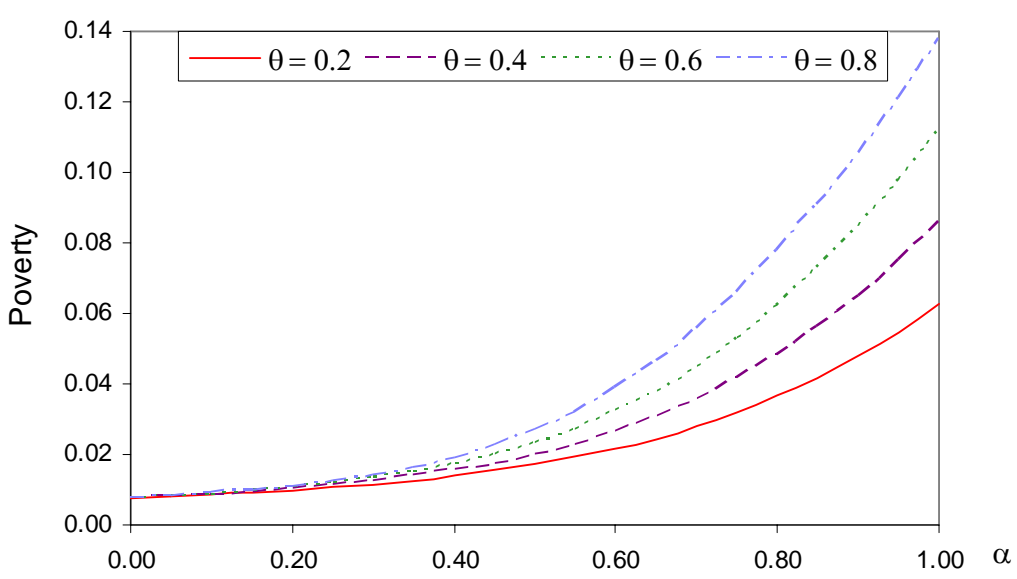

Figure 8 - Child $P_{1}$

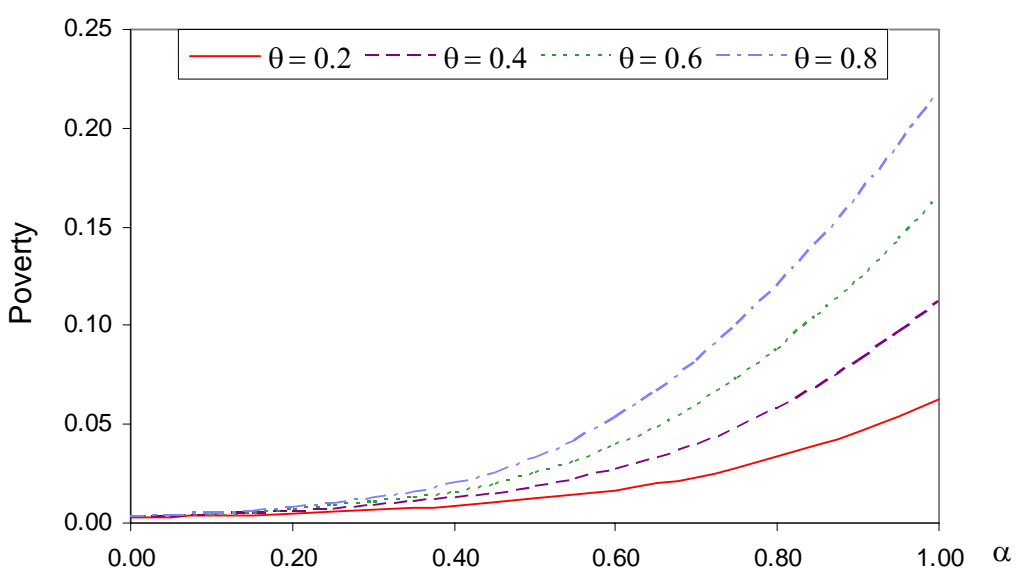


All figures show that poverty strictly rises with $\alpha$. This is a feature of the present data, as the relationship is not necessarily monotonic. Jointly considering the behaviour of the inequality and poverty measures, it may appear strange that inequality can fall at the same time as poverty rises, which is observed over low values of $\alpha$. However the two measures reflect separate effects on the distribution of equivalent income, $z$, of changes in the scale parameter. Changes in poverty are dominated by shifts in the distribution of equivalent income, while inequality changes are dominated by changes in its dispersion. When $\alpha$ is increased over low values, the concentration effect causes the distribution of equivalent income to become less skewed as inequality falls. At the same time poverty rises, as a greater area of the distribution falls below the poverty line. The behaviour of the distribution of equivalent income, $\mathrm{z}$, over low values of $\alpha$ is shown in Figure 9.

Figure 9 - Increasing $\alpha$ over Low Values

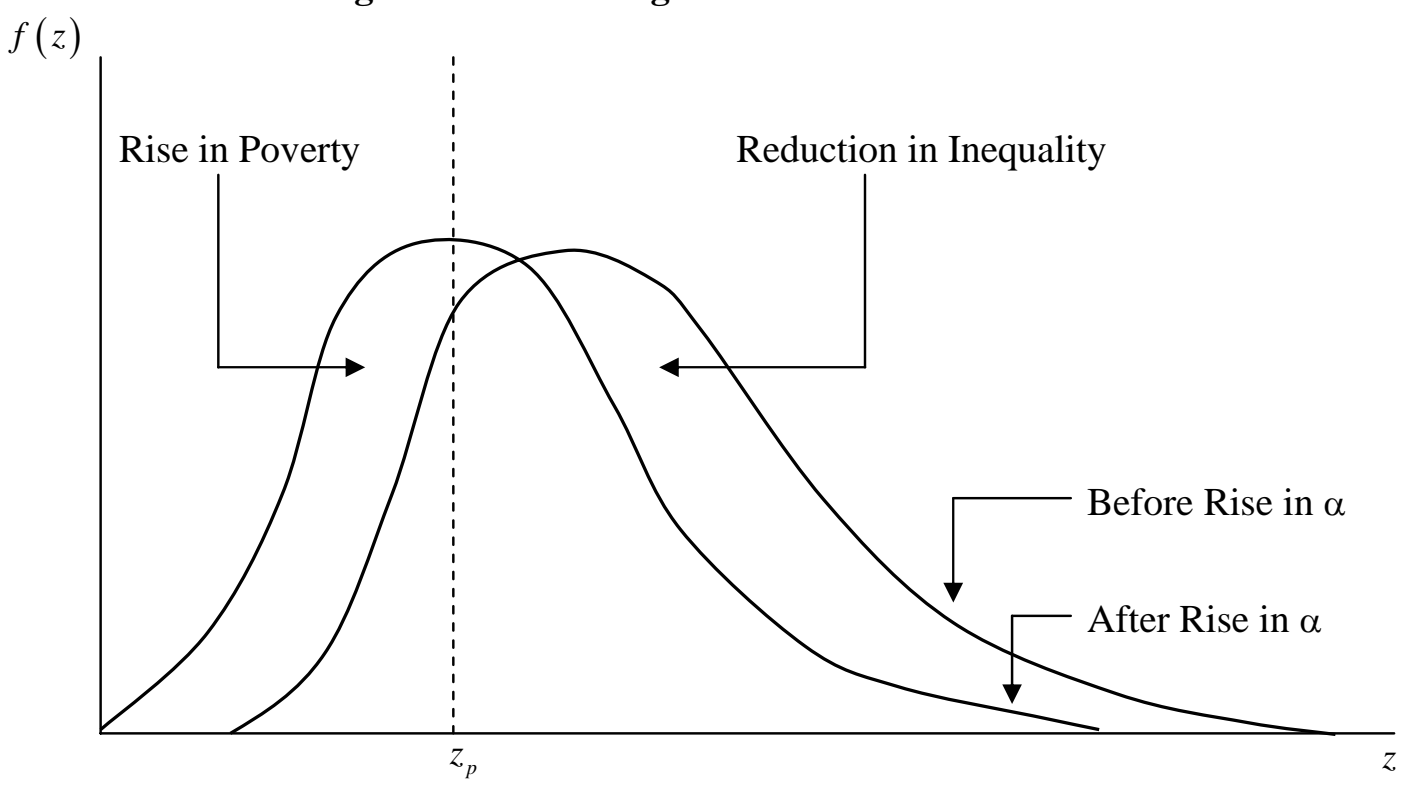

Once reranking (associated with the negative correlation between equivalent income and household size, discussed above) takes effect, increases in $\alpha$ cause inequality to rise, and the distribution of equivalent income becomes increasingly skewed. Again, poverty rises as the distribution continues to shift to the left. Figure 10 shows how the distribution of equivalent income changes as $\alpha$ is increased over higher values. 
Figure 10 - Increasing $\alpha$ over High Values

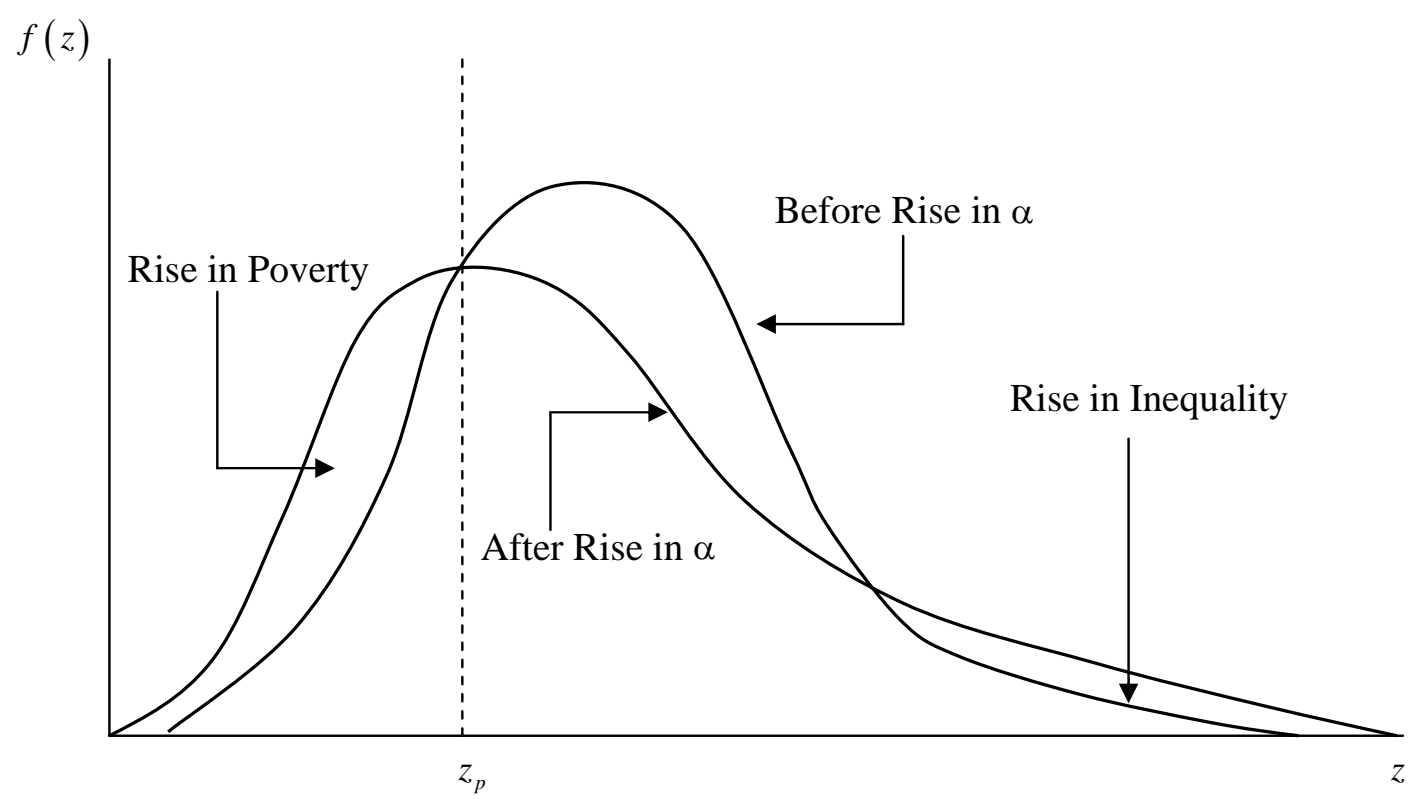

It is also of interest to consider whether poverty is higher when the child, as opposed to the individual, is used as the unit of analysis. Much attention is indeed given to child poverty in public debates. From Figures 5 to 8, it is clear that poverty is indeed higher over the higher ranges of $\alpha$, where there is a negative correlation between the equivalent income and the household size. Therefore larger households, those with more children, are likely to have lower equivalent incomes over the relevant range. A focus on children as the population group thus places relatively more units below any given poverty line. However, for lower values of $\alpha$ it has been seen above that there is a positive correlation between equivalent income and household size. Hence it is possible for poverty to be lower when the focus is on children only, compared with the use of all individuals. This is illustrated in Figure 11, which provides the $P_{1}$ poverty measure for both the individual and child units of analysis based on a poverty line of \$195 where the weight attached to children is $\theta=0.8$. The child unit of analysis produces lower measures of poverty over low levels of $\alpha$, but then increases at a greater rate as $\alpha$ is raised. 
Figure 11 - Poverty Measures, $P_{1}, z_{p}=\$ 195$ and $\theta=0.8$

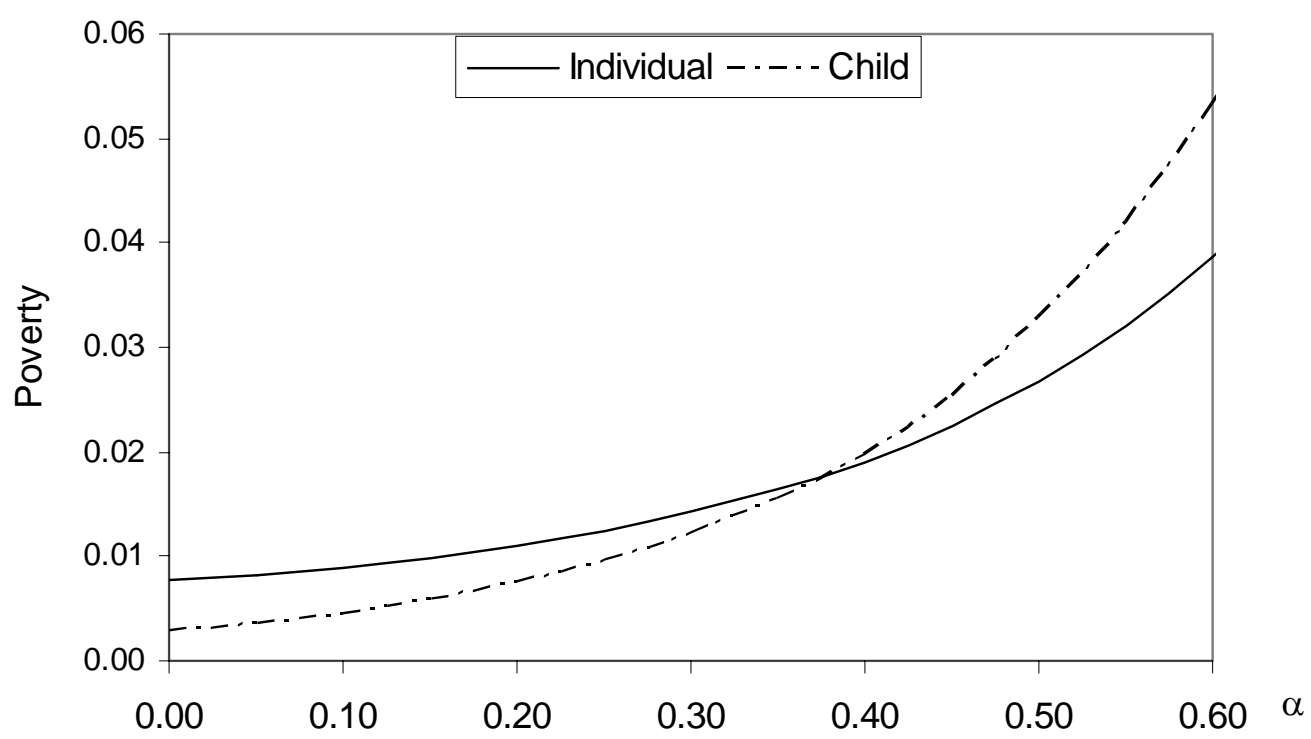

\section{Equivalence Scales and Direct Taxation}

This section considers the role of equivalence scales and the unit of analysis in the context of the effects of direct taxation. One effect of taxation is to cause a change in the rankings of households when moving from the pre-tax to the post-tax income distribution. ${ }^{10}$ The reranking of unadjusted incomes (that is total household income without any adjustment for size and composition) is of course a deliberate aim of the tax system, because the size and composition of households are considered as relevant non-income characteristics. Value judgements about the desirable redistribution arising from taxes and transfers are closely linked with such differences. In considering the tax treatment of those considered to be pre-tax 'equals', the equivalence scales determine the meaning attached to 'equality'. Reranking in terms of equivalent incomes cannot be expected to be zero, given that some reranking can also arise as the result of government policy that is not directly related to equity objectives. For example, unemployment benefits may be designed to encourage labour market participation, or certain types of income may be treated differently on efficiency grounds.

The reranking of equivalent incomes opposes the vertical redistributive effect of taxation, since an additional dispersion of pre-tax equals is introduced. It is therefore of interest to consider how it varies with the choice of adult equivalence scale. Following Atkinson (1979) and Plotnick (1981), reranking is defined as:

\footnotetext{
${ }^{10}$ This type of reranking is quite different from that discussed earlier, which was interpreted in terms of a negative correlation between equivalent income and household size.
} 


$$
R=G_{y}-C_{y}
$$

where $G_{y}$ is the Gini inequality measure of post-tax income, and $C_{y}$ is the concentration measure of post-tax income; this is obtained as a Gini-type measure, but with post-tax incomes ranked by pre-tax incomes.

In order to concentrate on direct taxes and transfers, the following results were obtained using information on the pre-tax annual incomes and disposable incomes of households in the 2001 Household Economic Survey. Figure 12 shows, for four values of $\theta$, the variation in reranking expressed as a percentage of the redistributive effect, $L$, measured as the difference between the Gini inquality of pre- and post-tax incomes, when individuals are regarded as the basic unit of analysis (income per adult equivalent is weighted by the number of individuals in the household). Figure 13 shows a similar pattern of reranking in the case where the basic income unit is the 'equivalent adult' and thus the number of equivalent adults is used as the weight for each household. While the variations in reranking are similar to those found in Figure 12, the values, as a percentage of redistribution, are systematically slightly lower in Figure 13.

These results show that the degree of reranking is relatively low. The profiles of reranking with variations in $\alpha$ are $\mathrm{U}$-shaped for the lower values of $\theta$ and become $\mathrm{J}$ shaped for higher values. For the range of values displayed here, reranking is lower for smaller values of $\theta$, the difference increasing for the higher $\alpha$. However, as $\theta$ is reduced further, below the lowest profile shown, the degree of reranking begins to increase: hence a reranking minimising set of equivalence scales exists for which $\theta>0$. It has been suggested by van de Ven and Creedy (2005) that a particular tax and transfer system can be identified with a set of implicit scales which are likely to be in the region of the rerankingminimising scales. It is not suggested that these necessarily reflect the value judgements of policy makers; indeed the analysis of such implicit scales can be useful in suggesting possible reforms to the tax structure, if they are found to deviate widely from actual value judgements. In the present context, where individuals are used as weights, minimum reranking was found for $\theta$ at around 0.05 and for $\alpha$ at around 0.45 . These values are obviously very different from those generally used in empirical studies and, in particular, involve a negligible weight attached to children. 
Figure 12 - Reranking, Unit of Analysis: Individual

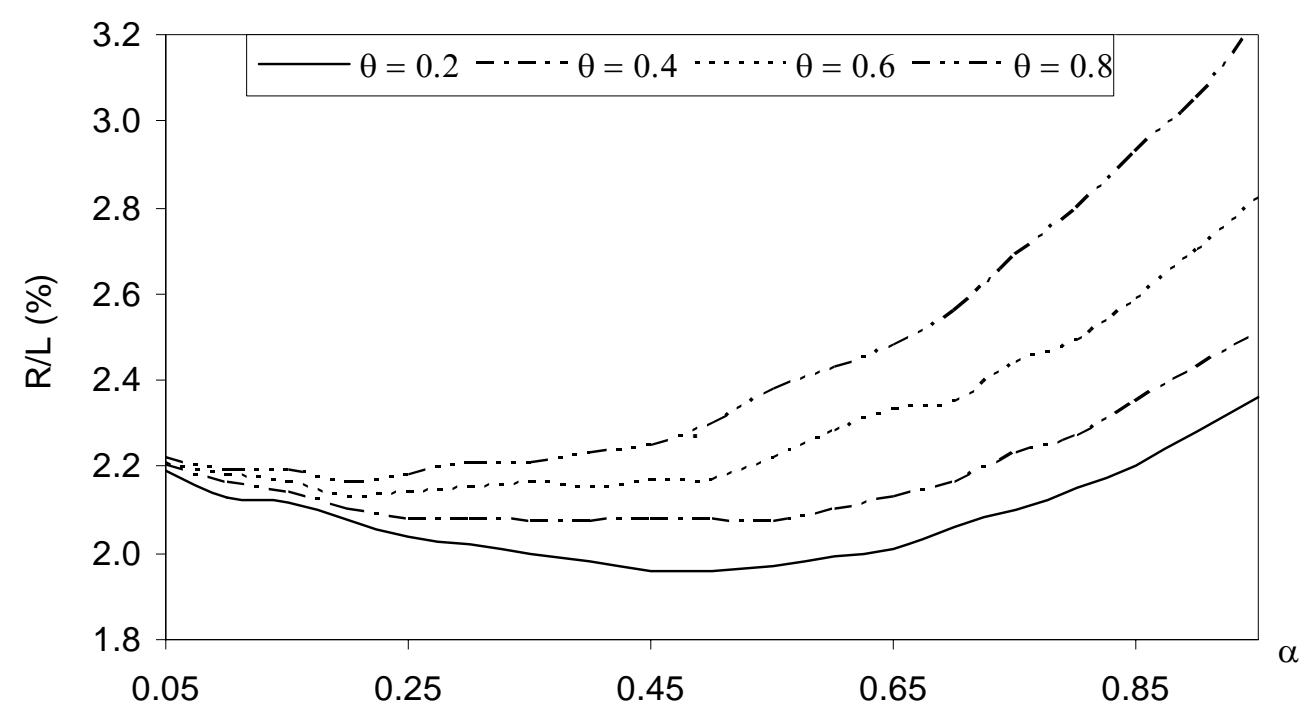

Figure 13 - Reranking, Unit of Analysis: Equivalent Adults

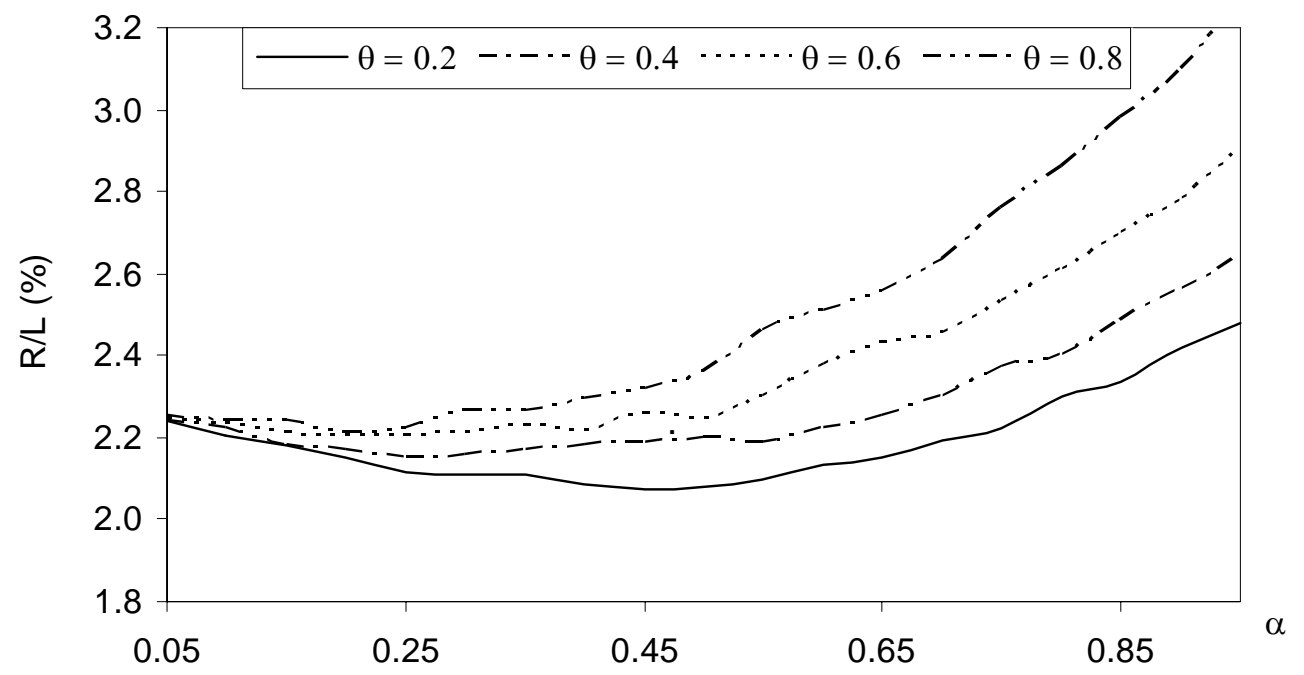

\section{Alternative Equivalence Scales}

This section contrasts inequality and poverty measures which arise from using alternative equivalence scales that appear in the literature. Appendix Table A1 describes 29 equivalence scales analysed. There is no suggestion that this is exhaustive as they consist of an arbitrary selection concentrating largely on New Zealand and Australia. The scales are grouped according to the regions for which they were designed and the sources from 
which they were obtained. ${ }^{11}$ In considering alternatives it should of course always be borne in mind that, as Cowell and Mercader-Prats (1999, p. 423) state, 'it is fanciful to suppose that equivalence scales can be constructed without the introduction of fundamental value judgements'.

As the equivalence scales are based on a variety of different approaches and functional forms, they are not directly comparable. However, it is possible to examine how closely they approximate the functional form used above by, for each scale, using the equivalent sizes, $m_{i}$, to fit the two-parameter form. This is achieved by carrying out regressions using the equation:

$$
\log m_{i}=\beta+\alpha \log \left(n_{a, i}+\theta n_{c, i}\right)+\psi_{i}
$$

As this equation is nonlinear in the parameters, regressions were carried out for a range of $\theta$ values, and the value producing the highest $R^{2}$ was taken as the required estimate, along with the corresponding value of $\alpha$. Appendix Table A1 shows the value of $R^{2}$ from these regressions together with the estimates of the parameters, $\theta$ and $\alpha$. As shown by the high values of $R^{2}$, the two-parameter form of equivalence scale provides a very good fit for all scales analysed; the lowest value of $R^{2}$ is 0.956 . Where NA is shown in the $R^{2}$ column (for scales 1, 2, 15 and 16), these scales were already based on the two parameter form and therefore no estimation was required.

There are substantial variations in the estimated values of $\theta$ and $\alpha$. The weight attached to children, $\theta$, ranges from 0.300 (scale no. 25) to 0.916 (scale no. 15), while the parameter reflecting economies of scale, $\alpha$, ranges from 0.395 (scale no. 14) to 1.014 (scale no. 13). Due to the nonlinear nature of the poverty and inequality profiles, observed variations in $\alpha$ and $\theta$ provide little indication as to the variation in inequality and poverty measures that would result from the different equivalence scales. For this reason, each scale was in turn applied to the New Zealand expenditure data, from which inequality and poverty measures were then calculated.

Figure 14 shows the inequality profiles produced using the equivalent adult unit of analysis and a high inequality aversion coefficient of 1.2, for four different values of $\theta$. Plotted on this figure are the measures of inequality produced using parameter estimates for each of the 29 equivalence scales. There is clearly a considerable range of inequality measures resulting from these scales. The two extremes are provided by scales 25 and 11, where inequality for the latter is 18 percent higher than for the former. Figure 14 shows

\footnotetext{
${ }^{11}$ As mentioned above, the scales are price independent, but of course differences in relative prices between countries may be thought to affect their applicability to more than one country.
} 
that a number of the scales differ mainly in the size of $\alpha$ and lie roughly on the relatively flat section of the inequality profiles, where inequality is not particularly responsive to changes in $\alpha$. The use of only those scales would give the misleading impression that the choice of scale is not important.

Consider scales 11, 12, 13 and 14 produced by Michelini (1999) for New Zealand. They all produce relatively high inequality measures. However, scale 14 is placed on the downward sloping segment of its inequality profile, while the others are on the upward sloping segment of their profiles. A comparison of those scales alone may also give the impression that inequality is not sensitive to a large variation in $\alpha$, whereas intermediate values would give substantially lower measures of inequality.

Figure 14 - Inequality, Unit of Analysis: Equivalent Adult, $\varepsilon=1.2$

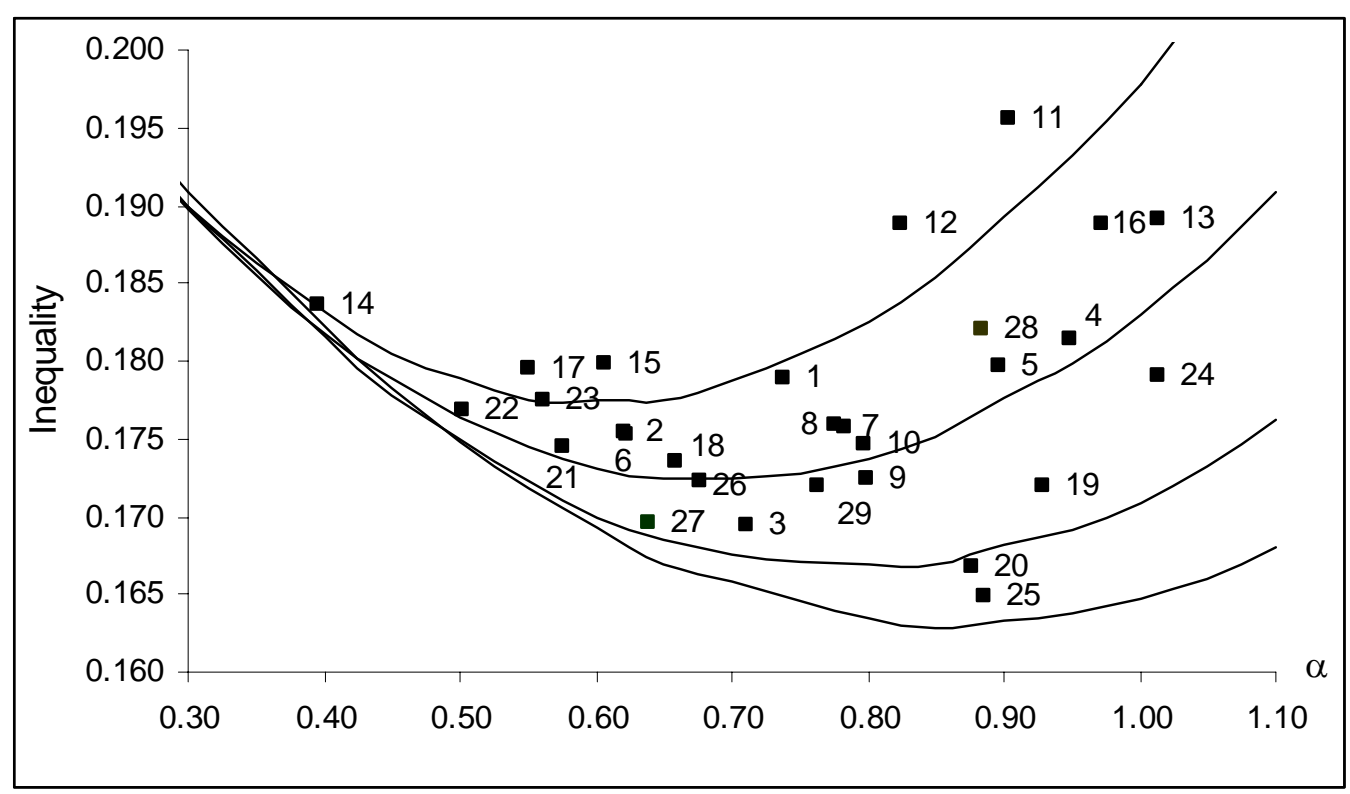

Figure 15 shows the profiles of the $P_{1}$ poverty measure, using the individual as the unit of analysis and a poverty line of \$195 per week. Plotted on this figure are the measures of poverty produced using each of the 29 equivalence scales. The variation in poverty is substantial. Further, the scales which produced inequality measures at either extreme of the distribution do not produce the extreme poverty measures. Instead, scales 14 and 13 provide the largest differential in poverty: when moving from the former to the latter, poverty increases by over 540 percent. It can also be seen that, whereas the Michelini scales 13 and 14 produce similar inequality measures - being on different sides of the Ushaped profiles - they produce substantially different poverty measures. It is clear that considerable care needs to be taken in comparing results for alternative scales, and in 
particular much caution is required before declaring that analyses are not affected by the choice of scale.

Figure 15 - Poverty - $P_{1}$, Unit of Analysis: Individual, $z_{p}=\$ 195$

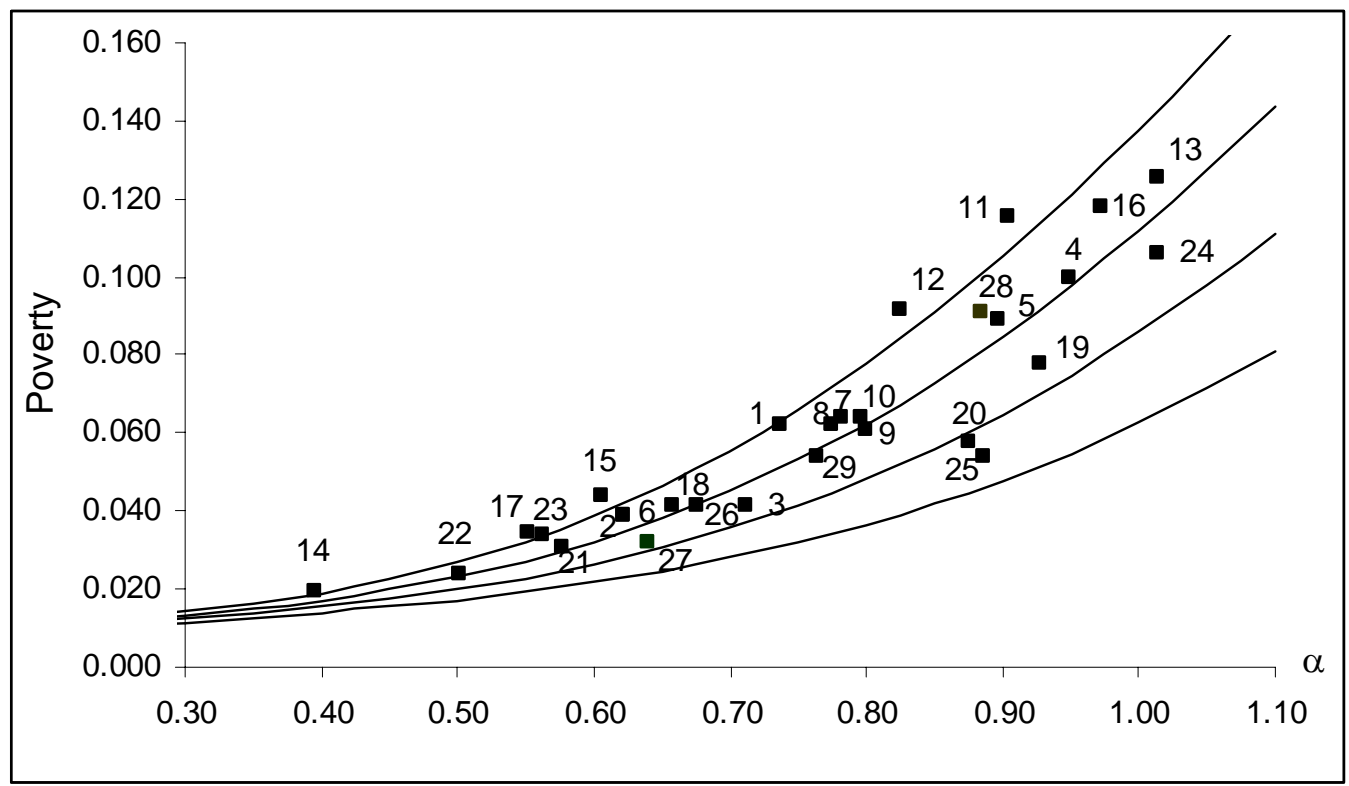

\section{Conclusions}

This paper has examined the sensitivity of several inequality and poverty measures to the choices of the adult equivalence scale and the unit of analysis. Use was made of a highly flexible two-parameter functional form of the adult equivalence scale, allowing for economies of scale in consumption and a separate weight added to children. Three units of analysis, namely the household, the equivalent adult and the individual were examined. The use of individuals is consistent with an anonymity principle, while the use of the number of equivalent adults is consistent with the principle of transfers.

Profiles of inequality against the economies of scale parameter, for a given weight attached to children, were found to be U-shaped, which is consistent with other studies. The role of the correlation between the total expenditure per equivalent adult and the size of the household was found to be crucial in generating the U-shape profile. A negative correlation (despite the positive correlation between total household expenditure and household size) is more likely, the lower is the weight attached to children and the higher is the economies of scale parameter. It was shown that a negative correlation is equivalent to the 'reranking', identified by Coulter et al (1992) that arises as the scale parameter increases. The profiles of inequality and poverty for individuals and equivalent adults as the units of analysis (or weights) were found to intersect over a range of parameter values. 
For poverty measures, the profiles of poverty with the economies of scale parameter were upward sloping, with a higher scale parameter increasing poverty over the whole range in all cases.

The effect of alternative equivalence scales and income units on the reranking arising from the direct tax system was also examined. Profiles of reranking for an increasing scale parameter were found to be J-shaped. A reranking minimising set of parameters were investigated, and were found to be substantially lower than scales commonly used in New Zealand. Finally, a wide range of equivalence scales designed for New Zealand, the United Kingdom, Australia and the OECD were examined. The twoparameter form provided a very good fit to these scales. The scales were applied to the New Zealand data and the resulting inequality and poverty measures were contrasted.

The results demonstrate that considerable care needs to be taken in the choice of adult equivalence scales and the income unit. Applied studies of inequality and poverty often use only a single set of scales, claiming that results are not affected. However, given the different patterns of variation in summary measures found, the results reinforce the suggestion of Coulter et al (1992) that much caution is required before declaring that analyses are not affected by the choice of scale. Some authors argue that, in making comparisons over time or between alternative tax structures, only the absolute values of inequality and poverty measures are affected, not the relative values. However, extensive analyses have shown that this comforting situation cannot be taken for granted. ${ }^{12}$ It is therefore useful to examine results for a range of scales and units of analysis, just as it has become common to use a range of inequality aversion parameters and summary measures.

\footnotetext{
${ }^{12}$ Creedy and Scutella (2004), examining a policy reform, found a variety of conflicts regarding the direction of changes in inequality and welfare, depending on the unit of analysis and equivalence scale used. A range of conflicts were also reported by Decoster and Ooge (2002).
} 


\section{Appendix}

Table A1 - Alternative Equivalence Scales and Regression Results

Scale No. Title

$\begin{array}{lll}\mathbf{R}^{2} & \theta & \alpha\end{array}$

New Zealand

Brashares, Edith and Aynsley, Maryanne (October 1990) Income Adequacy Standards for New Zealand

1 Jensen's 1978 Equivalence Scale

NA $\quad 0.781 \quad 0.737$

(Annex 5, p.1)

2 Jensen's 1988 Equivalence Scale

(Annex 5, p. 2)

NA $\quad 0.730 \quad 0.621$

Michelini, Claudio (April 1999) New Zealand Household Consumption Equivalence Scales from Quasi-Unit Record Data

3 Commodity-specific and household-type equivalence scales: ELES model

$0.999 \quad 0.490 \quad 0.711$ (p.14, Table 1 - Total Expenditure)

4 Estimates of the household Equivalence Scales for total consumption when the

$0.987 \quad 0.620 \quad 0.949$

equivalence parameter $m_{0}$ is commodity-invariant - $\operatorname{PS}-\operatorname{AID}\left(\theta_{\mathrm{j}}\right)$

(p.17, Table 2 - PS-AID $\left(\theta_{\mathrm{i}}\right)$

5 Estimates of the household Equivalence Scales for total consumption when the equivalence parameter $\mathrm{m}_{\mathrm{o}}$ is commodity-invariant - $\operatorname{PS}-\mathrm{QAID}\left(\theta_{\mathrm{j}}\right)$

(p.17, Table 2 - PS-QAID $\left(\theta_{\mathrm{j}}\right)$ )

6 Estimates of the household Equivalence Scales for total consumption when the equivalence parameter $\mathrm{m}_{\mathrm{o}}$ is commodity-invariant - PS-QAID $\left(\theta_{\mathrm{j}}\right)-\mathrm{H}$

(p.17, Table 2 - PS-QAID $\left(\theta_{\mathrm{i}}\right)$ - H)

Estimates of the household Equivalence Scales for total consumption when the equivalence parameter $\mathrm{m}_{\mathrm{o}}$ is commodity-invariant - $\operatorname{EPS}(\alpha)-\mathrm{QAID}\left(\theta_{\mathrm{j}}\right)$

(p.17, Table 2 - $\operatorname{EPS}(\alpha)$-QAID $\left.\left(\theta_{\mathrm{i}}\right)\right)$

Estimates of the household Equivalence Scales for total consumption when the equivalence parameter $m_{0}$ is commodity-invariant $-\operatorname{EPS}(\alpha)-\mathrm{QAID}\left(\theta_{\mathrm{j}}\right)^{\mathrm{d}}$

(p.17, Table 2 - $\left.\operatorname{EPS}(\alpha)-\mathrm{QAID}\left(\theta_{\mathrm{i}}\right)^{\mathrm{d}}\right)$

Estimates of the household Equivalence Scales for total consumption when the equivalence parameter $m_{0}$ is commodity-invariant $-\operatorname{EPS}(\beta, \lambda)-\operatorname{QAID}\left(\theta_{\mathrm{j}}\right)$

(p.17 Table 2 - $\left.\operatorname{EPS}(\beta, \lambda)-\mathrm{QAID}\left(\theta_{\mathrm{i}}\right)\right)$

Estimates of the household Equivalence Scales for total consumption when the equivalence parameter $m_{0}$ is commodity-invariant $-\operatorname{EPS}(\beta, \lambda)-\mathrm{QAID}\left(\theta_{\mathrm{j}}\right)^{\mathrm{d}}$

(p.17 Table 2 - $\left.\operatorname{EPS}(\beta, \lambda)-\mathrm{QAID}\left(\theta_{\mathrm{i}}\right)^{\mathrm{d}}\right)$

11 Commodity-specific and household-type equivalence scales obtained from the PS$\operatorname{AID}\left(\theta_{\mathrm{ij}}\right)$ model

(p.18, Table 3 - PS-AID $\left(\theta_{\mathrm{ij}}\right)$, Tot.Expenditure) 
$\begin{array}{lll}\mathbf{R}^{2} & \theta & \alpha\end{array}$

14 Commodity-specific and household-type equivalence scales obtained from the $\operatorname{EPS}(\beta, \lambda)$ -

$0.986 \quad 0.890 \quad 0.395$

QAID $\left(\theta_{\mathrm{ij}}\right)$ model

(p.20, Table 4 - $\operatorname{EPS}(\beta, \lambda)-\mathrm{QAID}\left(\theta_{\mathrm{ij}}\right)$, Tot.Expenditure)

15

16

Heuristic Household Equivalence Scales - Easton, 1980

(p.21, Table 6 - Easton, 1980)

(p.21, Table 6 - Smith, 1989)

\section{United Kingdom}

Brashares, Edith and Aynsley, Maryanne (October 1990) Income Adequacy Standards for New Zealand

Townsend's Equivalence Scale

(Annex 5, p.49, Table 38 - Townsend)

The United Kingdom Supplementary Benefit Equivalence Scale 1968/69

(Annex 5, p.49, Table 38 - Supplementary Benefit)

Van de Ven, Justin (November 18, 2003) Demand Based Equivalence Scale Estimates for Australia and the UK

NA $\quad 0.916 \quad 0.606$

NA $\quad 0.713 \quad 0.972$

$\begin{array}{lll}0.995 & 0.890 & 0.551 \\ 0.997 & 0.650 & 0.658\end{array}$

Equivalence Scales by Estimation Method for Engel Estimates for the UK (p.15, Table 3 - UK, Engel)

Equivalence Scales by Estimation Method for Rothbarth Estimates for the UK (p.15, Table 3 - UK, Rothbarth)

Equivalence Scales by Estimation Method for DS(a) Estimates for the UK (p.15, Table 3 - UK, DS(a))

Equivalence Scales by Estimation Method for DS(b) Estimates for the UK (p.15, Table 3 - UK, DS(b))

$0.999 \quad 0.470 \quad 0.928$

$0.997 \quad 0.370 \quad 0.876$

$\begin{array}{lll}1.000 & 0.630 & 0.576\end{array}$

$\begin{array}{lll}1.000 & 0.640 & 0.501\end{array}$

\section{Australia}

Brashares, Edith and Aynsley, Maryanne (October 1990) Income Adequacy Standards for New Zealand

Henderson Equivalence Scale

(Annex 5, p.40, Table 30 - Head Working - All Costs)

$0.989 \quad 0.810 \quad 0.562$

Van de Ven, Justin (November 18, 2003) Demand Based Equivalence Scale Estimates for Australia and the UK

Equivalence Scales by Estimation Method for Engel Estimates for Australia

0.999

$0.530 \quad 1.013$

(p.15, Table 3 - Australia, Engel)

Equivalence Scales by Estimation Method for Rothbarth Estimates for Australia (p.15, Table 3 - Australia, Rothbarth)

$0.994 \quad 0.300 \quad 0.886$

Equivalence Scales by Estimation Method for DS(a) Estimates for Australia

$\begin{array}{lll}1.000 & 0.600 & 0.676\end{array}$

(p.15, Table 3 - Australia, DS(a))

Equivalence Scales by Estimation Method for DS(b) Estimates for Australia (p.15, Table 3 - Australia, DS(b)

$0.999 \quad 0.470 \quad 0.639$

\section{OECD}

The OECD scale

0.998

$0.700 \quad 0.884$

(p.172)

The Modified OECD scale

$\begin{array}{lll}0.994 & 0.580 & 0.763\end{array}$ 


\section{References}

Atkinson, A.B. (1979) Horizontal equity and the distribution of the tax burden. In: Aaron, H.J. and Boskins, M.J. (eds), The Economics of Taxation. Washington: The Brookings Institution.

Attanasio, O. P. and Japelli, T. (1997) The life cycle hypothesis and consumption inequality. Institute For Fiscal Studies Working Paper, W97/17.

Banks, J. and Johnson, P. (1994) Equivalence scale relativities revisited. Economic Journal, 104, pp. 883-890.

Blundell, R. and Preston, I. (1994) Income or consumption in the measurement of inequality and poverty. Institute For Fiscal Studies Working Paper, W94/12.

Blundell, R. and Preston, I. (1997) Consumption inequality and economic uncertainty. Institute For Fiscal Studies Working Paper, W97/15.

Brashares, E. and Aynsley, M. (1990) Income adequacy standards for New Zealand. (New Zealand Treasury internal paper).

Buhmann, B., Rainwater, L., Schmaus, G. and Smeeding, T. M. (1988) Equivalence scales, well-being, inequality, and poverty: Sensitivity estimates across ten countries using the Luxembourg income study (LIS) database. Review of Income and Wealth, 34, pp. 115-142.

Coulter, A. E., Cowell, F. A. and Jenkins, S. P. (1992) Equivalence scale relativities and the extent of inequality and poverty. Economic Journal, 102, pp. 1067-1082.

Cowell, F. A. (1984) The structure of American income inequality. Review of Income and Wealth, 30, pp. 351-375.

Cowell, F. A. and Mercader-Prats, M. (1999) Equivalence scales and inequality. In Handbook on Income Inequality Measurement (ed. by J. Silber), pp. 405-435. Boston: Kluwer.

Creedy, J. and Scutella, R. (2004) The role of the unit of analysis in policy reform evaluations of inequality and social welfare. Australian Journal of Labour Economics, 7, pp. 89-108.

Cutler, D. M. and Katz, L. (1992) Rising inequality? Changes in the distribution of income and consumption in the 1980s. American Economic Review, 82, pp. 546-551. 
Danziger, S. and Taussig, M. K. (1979) The income unit and the anatomy of income distribution. Review of Income and Wealth, 25, pp. 365-375.

Decoster, A. and Ooghe, E. (2002) Weighting with individuals, equivalent individuals or not weighting at all: does it matter empirically? Catholic University of Leuven Centre for Economic Studies Discussion Paper, DPS 02.15.

Ebert, U. (1997) Social welfare when needs differ: an axiomatic approach. Economica, 64, pp. 233-244.

Foster, J., Greer, J. and Thorbecke, E. (1984) A class of decomposable poverty measures. Econometrica, 52, pp. 761-762.

Glewwe, P. (1991) Household equivalence scales and the measurement of inequality: transfers from the poor to the rich could decrease inequality. Journal of Public Economics, 44, pp. 214-216.

Jenkins, S. P. and Cowell, F. A. (1994) Parametric equivalence scales and scale relativities. Economic Journal, 104, pp. 891-900.

Jorgenson, D. W. and Slesnick, D. T. (1984) Aggregate consumer behaviour and the measurement of inequality. Review of Economic Studies, 51, pp. 369-392.

Michelini, C. (1999) New Zealand Household consumption equivalence scales from quasiunit record data. Massey University Department of Applied and International Economics Discussion Paper, no. 99.02.

Plotnick, R. (1981) A measure of horizontal inequity. Review of Economics and Statistics, 63, pp. 283-288.

Ringen, S. (1991) Households, standard of living and inequality. Review of Income and Wealth, 37, pp. 1-13.

Shorrocks, A. F. (2004) Inequality and welfare evaluation of heterogeneous income distributions. Journal of Economic Inequality, 2, pp. 193-218.

Slesnick, D. T. (1994) Consumption, needs and inequality. International Economic Review, 35, pp. 677-703.

Trigger, D. (2003) Does the way we measure poverty matter? Natsem Discussion Paper, no. 59.

van de Ven, J. Demand based equivalence scale estimates for Australia and the UK. (Unpublished paper) 
van de Ven, J. and Creedy, J. (2005) Taxation, Reranking and Equivalence Scales. Bulletin of Economic Research, 57, pp. 13-36

Whiteford, P. (1985) A family's needs: equivalence scales, poverty and social security. Department of Social Security Research paper No.27. Canberra: Australia. 